\title{
The Relationship between Farming Experiences and Attitudes Toward Locally Grown Foods Among Japanese Children
}

\author{
Takaho Taniguchi ${ }^{1}$ and Rie Akamatsu ${ }^{2,3}$
}

ADDITIONAL INDEX WORDs. agriculture, elementary school students, attachment to region

SUMMARY. In Japan, introducing farming experiences in the context of school has become popular in promoting "locally produced, locally consumed" foods. This study examined the relationship between farming experience and "attitudes toward locally grown foods" and "attachment to region" among Japanese children. In total, 1464 fifth-grade children in Japan participated in this study and completed questionnaires on their farming experiences, attitudes toward locally grown foods, and attachment to the region in which they live. The scales concerning "attitudes toward locally grown foods" and "attachment to region" were scored, and the scores were compared according to whether the child had farming experience using the Kruskal-Wallis test. About one-quarter of the children (25.6\%) responded that they "very often" had farming experiences, and the scores for "attitudes toward locally grown foods" and "attachment to the region" were highest among the children who answered that they had experienced farming "very often" (both $P<0.001$ ). Additionally, significant positive relationships between farming experience and "attitudes toward locally grown foods" (partial correlation coefficient $r=0.171, P<$ $0.001)$ and "attachment to region" $(r=0.156, P<0.012)$ were found, even after adjusting for demographic characteristics. The results suggest that having the opportunity to experience farming was associated with more positive attitudes toward locally grown foods and the sense of attachment to one's region among children.

$\mathrm{T}$ The movement among educators to include gardening or farming experiences in educational programs that promote health has been growing. Despite several limitations to previous studies, a systematic review showed that garden- or farm-based educational programs may have the potential to improve children's fruit and vegetable intake (Robinson-O'Brien et al., 2009). These previous studies attempted to assess cognitive factors related to fruit and vegetable intake (Robinson-O'Brien et al., 2009). For example, recent studies have also reported that knowledge (e.g., the ability to identify fruit and vegetables and the benefits of eating fruit and vegetables), competence (e.g., the ability to prepare fruit or vegetables for meals), attitudes (e.g., fruit and vegetable preferences),

This study was funded by the educational farm program sponsored by the Ministry of Agriculture, Forestry and Fisheries of Japan.

${ }^{1}$ Graduate Student, Graduate School of Humanities and Sciences, Ochanomizu University, Otsuka 2-1-1, Bunkyo-ku, Tokyo 112-8610, Japan

${ }^{2}$ Associate Professor, Graduate School of Humanities and Sciences, Ochanomizu University, Otsuka 2-1-1, Bunkyo-ku, Tokyo 112-8610, Japan

${ }^{3}$ Corresponding author. E-mail: akamatsu.rie@ocha.ac.jp. and intentions (e.g., willingness to taste fruit and vegetables) increased after participation in school-based garden programs (Heim et al., 2009; Koch et al., 2006; Lineberger and Zajicek, 2000; Parmer et al., 2009; Somerset and Markwell, 2009).

In addition to programs related to promoting fruit and vegetable intake, garden- or farm-based educational programs have received attention in relation to a wide range of children's behaviors. Robinson and Zajicek (2005) reported that scores on tests measuring life skills increased after participation in a garden program. Improvements were especially pronounced with respect to working with groups (e.g., "I can work with other people") and selfunderstanding (e.g., "I try very hard to do my best") (Robinson and Zajicek, 2005). Another study reported improved self-esteem, community spirit, and leadership skills (National Gardening Association, 2007).

In Japan, it has also been recognized that farm-based educational programs could be linked to improving factors other than those related to children's attitudes and behaviors. In particular, the promotion of chisan- chisho, which means "locally produced, locally consumed," has become popular in Japan (Kimura and Nishimura, 2008). The concept of chisan-chisho also exists in the United States under the label of "locavore," a national movement originating in San Francisco in 2005 that promotes the consumption of only those foods grown or harvested within a 100 -mile radius (Locavores, 2010). This movement advocates adherence to the locavore philosophy on the basis of political, environmental, economic, and health-related considerations.

The Japanese government promotes chisan-chisho to increase selfsufficiency with respect to food production. Foods originating in Japan accounted for only $40 \%$ of the total calories consumed in this country in 2009 [Japan Ministry of Agriculture, Forestry and Fisheries (MAFF), 2010]. Therefore, Japan promotes using locally grown foods for school lunches and for use in restaurants (Sasaki, 2002; Yamamoto et al., 2007). The consumption of locally grown foods is also expected to support the development of ecologically sustainable food systems (Gill, 2006).

To promote chisan-chisho, the Japanese government stipulated that classes be taught by local farmers at their farms and that participants learn about agriculture by cultivating crops at least twice per year to enhance the sense of attachment to one's region (MAFF, 2006). Farmers expect children to consume their products more readily and teachers expect students to perform better in their classes (e.g., in social studies and science classes) when experiential connections have been established. Thus, these programs have attracted the attention of both teachers and farmers, with more than 10,000 students and $\approx 1000$ farmers participating in the educational farms from 2008 to 2009 (Rural Culture Association, 2010).

Although the consumption of locally grown foods has been widely promoted, little research has examined the relationship between farming experience and attitudes toward locally grown foods and the presumably related attachment to one's own region. The present study examines the association between farming experience and attitudes toward locally grown foods and sense of attachment to one's region. 


\section{Materials and methods Design and participants}

This study used the baseline data from the educational farm program conducted by MAFF (2006). A total of 1485 fifth-grade elementary school students who applied to participate in the program from 12 schools in Fukushima Prefecture, three schools in Saitama Prefecture, two schools in Wakayama Prefecture, and seven schools in Kumamoto Prefecture completed self-report questionnaires and in-class surveys between May and June, 2008, before the educational farm program was initiated. Kumamoto Prefecture is rural, and Saitama Prefecture is urban, and the other two prefectures rank somewhere in the middle in terms of population (Japan Ministry of Internal Affairs and Communications, 2009).

\section{Procedure}

The survey's procedure, including the explanation to students, was based on a guidance document describing the standardization of the survey method. Teachers explained the purpose of the study to the students, and the survey was kept completely separate from their classes or school records. Students could refuse to participate in the survey without penalty. Because the questionnaire included items concerning personal information (e.g., height and weight), all responses were kept anonymous. The study was approved by the Ethics Committee of Ochanomizu University.

\section{Measures}

The face validity of the questionnaire was tested in a pilot study involving 194 public school students in Saitama in the same grade as the participants in this study who did not participate in the subsequent research. The current study collected data on demographic characteristics including sex, height, weight, and region, as well as on the following issues:

FARMING EXPERIENCE (ONE ITEM). Japanese people expected that farming would promote chisan-chisho, so farming experience in the context of school was investigated. The children were asked to respond to the following statement: "I have experienced farming in class and in school activities before." Response categories included 1) not at all, 2) a little, 3) somewhat 4), and 4) very often.
AtTitudes TOWARD LOCALly GROWN FOODS (FIVE ITEMS). The items about attitudes toward locally grown foods were developed in the context of experience with educational farm programs (MAFF, 2006). The children were asked to indicate the degree to which the following statements were true: "I know the food produced in the region where I live," "I like the food that is produced in the region where I live," "I think the food produced in the region where I live is delicious," "I often eat the food that is produced in the region where I live," and "I am aware of the season when I eat food." Response categories included 1) disagree, 2) disagree a little, 3 ) agree a little, and 4) agree.

AtTAChment to Region (FIVE ITEMS). The Japanese believe that people with a strong relationship to a region have more positive attitudes toward locally grown foods. Participants were asked about five items related to their sense of attachment to their region, which were developed through educational farm programs (MAFF, 2006): "I love the region I live in," "I want to continue to live in the region when I am an adult," "I know the local festivals and events," "I participate in local festivals and events," and "I often talk with neighbors." Response categories included 1) disagree, 2) disagree a little, 3 ) agree a little, and 4) agree.

\section{Data analysis}

Because the scores for "attitude toward locally grown food," "attachment to region," and body mass index (BMI) all showed asymmetrical distributions $(P=0.001$, based on the results of the Shapiro-Wilk test), the median within a percentile range (25th and 75th percentile values) and a nonparametric analysis, which is a distributionfree method, were used for statistical analyses (Altman et al., 2000).

First, data on participants' characteristics were analyzed. Then, relationships between the frequency of farming experiences and participant characteristics were examined using the chi square test for sex and region and the Kruskal-Wallis test for BMI.

After the internal consistency of each scale ("attitudes toward locally grown food" and "attachment to region") was confirmed, the total score of each scale was presented in terms of the median and the 25th and 75th percentile values. Next, the scores were compared by sex using the MannWhitney $U$ test.

The association between "attitudes toward locally grown food" and "attachment to region" was examined using the Spearman correlation coefficient $(r)$. To examine the correlations between the frequency of farming experiences by "attitudes toward locally grown foods" and "attachment to region," the Kruskal-Wallis test and Steel-Dwass method for multiple comparisons were used for quantitative data.

Finally, the association between farming experiences and "attitudes toward locally grown food" and "attachment to region" was examined using the partial correlation coefficient after adjusting for demographic characteristics (sex, region, and BMI). Dummy variables for categorical data were subjected to binary adjustments.

SPSS (release 19.0 for Windows; IBM Japan, Tokyo, Japan) was used in the analysis, and an $\alpha$ level of $<0.05$ was selected to indicate statistical significance. Missing data were excluded from each analysis.

\section{Results and discussion}

A total of 1464 children completed all questionnaire items (response rate, $98.6 \%)$. A total of 751 boys $(51.3 \%)$ and 700 girls $(47.8 \%)$ responded [ missing data $=13(0.9 \%)$ ]. Subjects lived in Fukushima [ $n=286$ $(19.5 \%)]$, Saitama [ $n=438(29.9 \%)]$, Wakayama $[n=71(4.8 \%)]$, and Kumamoto $[n=669(45.7 \%)]$ prefectures. The median (25th/75th percentile values) BMI was 16.8 (15.5/ 18.5 , respectively), which was slightly lower than the national average (the average BMI of 10-year-old boys was 18.1 and that of 10-year-old girls was 17.4) (Japan Ministry of Health, Labour and Welfare, 2010).

DEMOGRAPHIC COMPARISONS. Farming experience was reported as follows: $325(22.2 \%)$ "not at all," 278 (19.0\%) “a little," 471 (32.2\%) "somewhat," and 373 (25.6\%) "very often" [ $15(1.0 \%)$ were missing data]. Table 1 shows the characteristics of the participants according to farming experience. Girls were more likely than boys to answer that they had experienced farming $\left[\chi^{2}(3)=9.5, P=\right.$ $0.024]$. The distribution also differed by region $\left[\chi^{2}(9)=323.9, P<0.001\right]$. Because Saitama is the most highly urbanized area of the four regions in this study, more than $50 \%$ of children 
in Saitama responded that they had no farming experience. No differences were found in BMI $\left[\chi^{2}(3)=2.6, P=\right.$ $0.46]$ according to farming experience. The median (25th/75th percentile values) BMIs by farming experience were as follows: "not at all" 16.5 (15.3/18.5), “a little” 17.1 (15.6/ 18.5), "somewhat" 16.7 (15.5/18.3), and "very often" 16.8 (15.5/18.7).

AtTitudes toward LOCALly GROWN FOODS AND ATTACHMENT TO REGION. According to Cronbach's alpha, the internal consistency of each scale "attitudes toward locally grown foods" and "attachment to region" was 0.81 and 0.67 , respectively.

The median (25th/75th percentile values, minimum-maximum) scores for the two scales of interest were as follows: "attitudes toward locally grown foods," $15(13 / 18,5-20)$ and "attachment to region," $16(13 / 18,5-20)$, whereas higher scores showed a more positive "attitude toward locally grown foods" or greater "attachment to region." A moderate relationship was found between the two scales $(r=$ $0.592 ; P<0.001)$.

Girls' "attitudes toward locally grown foods" were more positive (16, 13-18) than those of boys' (15, 12-17) $(P=0.001)$; on the other hand, girls (16, 14-18) and boys $(16,13-18)$ did not differ with respect to "attachment to region" $(P=$ 0.080 ).

RELATIONSHIPS BETWEEN FARMING EXPERIENCE AND ATTITUDES TOWARD LOCALLY GROWN FOODS AND ATTACHMENT TO REgION. Table 2 shows the scores by farming experience. The scores were significantly different according to farming experience ["attitudes toward locally grown foods" $\chi^{2}(3)=82.5, P<0.001$; "attachment to region" $\left.\chi^{2}(3)=42.1, P<0.001\right]$. Higher scores on both scales were found for children who answered that they had experienced farming "very often."

The partial correlation coefficients for farming experience were as follows: "attitudes toward locally grown foods" $0.171(P<0.001)$; "attachment to region" $0.156(P<$ $0.001)$. Although the partial correlation coefficients were low, "attitudes toward locally grown foods" and "attachment to region" were associated with farming experience even after adjusting for demographic characteristics.

Table 1. Chi square test comparison of sex and region by farming experience among fifth-grade elementary school students in Japan.

\begin{tabular}{|c|c|c|c|c|c|c|c|c|c|}
\hline & \multicolumn{8}{|c|}{ Farming experience } & \multirow[b]{3}{*}{$P$} \\
\hline & \multicolumn{2}{|c|}{ Not at all } & \multicolumn{2}{|c|}{ A little } & \multicolumn{2}{|c|}{ Somewhat } & \multicolumn{2}{|c|}{ Very often } & \\
\hline & no. & $\%$ & no. & $\%$ & no. & $\%$ & no. & $\%$ & \\
\hline \multicolumn{10}{|l|}{ Gender } \\
\hline Boys & 188 & 58.4 & 144 & 52.2 & 230 & 49.4 & 177 & 47.5 & $0.024^{*}$ \\
\hline Girls & 134 & 41.6 & 132 & 47.8 & 236 & 50.6 & 196 & 52.5 & \\
\hline \multicolumn{10}{|l|}{ Region } \\
\hline Fukushima & 20 & 6.2 & 24 & 8.6 & 81 & 17.2 & 157 & 41.9 & $0.000 * * *$ \\
\hline Saitama & 185 & 56.9 & 90 & 32.4 & 112 & 23.8 & 46 & 12.3 & \\
\hline Wakayama & 9 & 0.9 & 5 & 1.8 & 45 & 9.6 & 18 & 4.8 & \\
\hline Kumamoto & 117 & 36.0 & 159 & 57.2 & 233 & 49.5 & 154 & 41.1 & \\
\hline
\end{tabular}

${ }^{*},{ }^{* * *}$ Significant at $P \leq 0.05,0.001$, respectively.

Table 2. Kruskal-Wallis comparison of scores on "attitudes toward locally grown foods" and "attachment to region" by farming experience among fifth-grade elementary school students in Japan.

\begin{tabular}{llccccc}
\hline Scale & $\begin{array}{c}\text { Farming } \\
\text { experience }\end{array}$ & Median $^{\text {z }}$ & $\begin{array}{c}\text { 25th/75th } \\
\text { percentile } \\
\text { values }\end{array}$ & df & $\begin{array}{c}\text { Kruskal- } \\
\text { Wallis, H }\end{array}$ & $P$ \\
\hline Attitudes toward & Not at all & $14 \mathrm{ab}^{\mathrm{y}}$ & $11 / 16$ & 3 & 82.54 & $0.000^{* * *}$ \\
locally grown & A little & $15 \mathrm{a}$ & $13 / 17$ & & & \\
foods & Somewhat & $15 \mathrm{bc}$ & $13 / 18$ & & & \\
& Very often & $17 \mathrm{ac}$ & $14 / 19$ & & & \\
Attachment & Not at all & $15 \mathrm{ab}$ & $12 / 17$ & 3 & 42.11 & $0.000^{* * *}$ \\
to region & A little & $15 \mathrm{c}$ & $13 / 17$ & & & \\
& Somewhat & $16 \mathrm{a}$ & $14 / 18$ & & & \\
& Very often & $17 \mathrm{bc}$ & $14 / 18$ & & & \\
\hline
\end{tabular}

${ }^{\mathrm{z}}$ Scores ranged from 5 to 20 .

${ }^{y}$ Results of post hoc comparisons of medians. Medians with the same superscript letters are significantly different at $P \leq 0.008=0.05 / 6$ (Steel-Dwass method).

$* *$ Significant at $P \leq 0.001$

\section{Conclusions}

This study examined the relationship between farming experience and "attitudes toward locally grown foods" and "attachment to region" among Japanese children. The results suggest that having the opportunity to experience farming may promote positive attitudes toward locally grown foods and attachment to the region in which one lives. It would be interesting to find out whether positive attitudes toward locally grown foods actually promote eating local food.

This study has several limitations. First, these results should be interpreted with caution due to the nature of selfreported data. Second, this study was cross-sectional, and causal associations were therefore unclear; however, it is important to note that a positive relationship between farming experience and "attitudes toward locally grown foods" and "attachment to region" was found. Only four regions in Japan participated in this study, so the generalizability of these results is limited. This study cannot determine how these two factors may influence the behavior of children in the future.

The advancement of globalization renders international foods easy to obtain, which may lead to a decrease in food self-sufficiency, as in Japan, and this in turn may result in declining populations in rural towns. This study suggests that collaboration between schools and local communities may support child development and local revitalization through farming programs. Investigation of whether attachment to region promotes local revitalization, which was related to "attitudes toward locally grown foods," may prove useful. Moreover, the examination of attitudes toward locally grown foods in other countries with the same problem may prove informative.

\section{Literature cited}

Altman, D.G., S.M. Gore, M.J. Gardner, and S.J. Pocock. 2000. Statistical guidelines 
for contributors to medical journals, $\mathrm{p}$. 171-190. In: D.G. Altman, D. Machin, T.N. Bryant, and M.J. Gardner (eds.). Statistics with confidence, 2nd ed. BMJ Books, Bristol, United Kingdom.

Gill, S. 2006. Ecological citizenship and sustainable consumption: Examination of local organic food networks. J. Rural Stud. 22(4):383-395.

Heim, S., J. Stang, and M. Ireland. 2009. A garden pilot project enhances fruit and vegetable consumption among children. J. Amer. Dietetic Assn. 109(7):1220-1226.

Japan Ministry of Agriculture, Forestry and Fisheries. 2006. GO! GO! Educational farming. Casebook of educational farming. Ministry of Agriculture, Forestry and Fisheries, Tokyo. (in Japanese).

Japan Ministry of Agriculture, Forestry and Fisheries. 2010. The self-sufficiency rate of food in Japan. 29 Mar. 2011. <http:// www.maff.go.jp/index.html>. (in Japanese).

Japan Ministry of Health, Labour and Welfare. 2010. The national health and nutrition survey in Japan, 2007. Daiichishuppan, Tokyo. (in Japanese).

Japan Ministry of Internal Affairs and Communications. 2009. Statistical observations of prefectures in Japan. Ministry of
Internal Affairs and Communications, Tokyo. (in Japanese).

Kimura, H.A. and M. Nishimura. 2008. The chisan-chisho movement: Japanese local food movement and its challenges. Agr. Human Values 25(1):49-64.

Koch, S., T.M. Waliczek, and J.M. Zajicek. 2006. The effect of a summer garden program on the nutritional knowledge, attitudes, and behaviors of children. HortTechnology 16:620-625.

Lineberger, S.E. and J.M. Zajicek. 2000. School gardens: Can a hands-on teaching tool affect students' attitudes and behaviors regarding fruit and vegetables? HortTechnology 10:593-597.

Locavores. 2010. Locavores. 6 June 2010. <http://www.locavores.com/>.

National Gardening Association. 2007. Evaluation summary. 20 Apr. 2010 <http://www.kidsgardening.com/grants/ 2007-evaluation-summary.asp $>$.

Parmer, S.M., J. Salisbury-Glennon, D. Shannon, and B. Struempler. 2009. School gardens: An experiential learning approach for a nutrition education program to increase fruit and vegetable knowledge, preference, and consumption among second-grade students. J. Nutr. Educ. Behav. 41(3):212-217.
Robinson, C.W. and J.M. Zajicek. 2005. Growing minds: The effects of a one-year school garden program on six constructs of life skills of elementary school children. HortTechnology 15:453-457.

Robinson-O'Brien, R., M. Story, and S. Heim. 2009. Impact of garden-based youth nutrition intervention programs: A review. J. Amer. Dietetic Assn. 109(2):273280.

Rural Culture Association. 2010. Educational farm net. 20 Apr. 2010. <http:// www.edufarm.jp/>.

Sasaki, T. 2002. Fast development of the "consuming-products-at-their-origin" movement and possibilities for environment counter. Bul. Nippon Veterinary Animal Sci. Univ. 51:11-23. (in Japanese).

Somerset, S. and K. Markwell. 2009. Impact of a school-based food garden on attitudes and identification skills regarding vegetables and fruit: A 12-month intervention trial. Public Health Nutr. 12(2):214221.

Yamamoto, N., Y. Yamane, and S. Kobaye. 2007. Consumers' needs for farmers' markets and conditions for their establishment. Bul. Fac. Agr. Univ. Miyazaki 55(1/2):7783. (in Japanese). 